\title{
Research on Course Teaching Design in Universities of China Based on the Flipped Classroom
}

\author{
Xinjian Qiang ${ }^{a}$, Guojian Cheng ${ }^{b}$, Ye Liu ${ }^{c}$ and Xiaoying Yan ${ }^{d}$ \\ School of Computer Science, Xi'an Shiyou University, Xi'an, Shaanxi, China

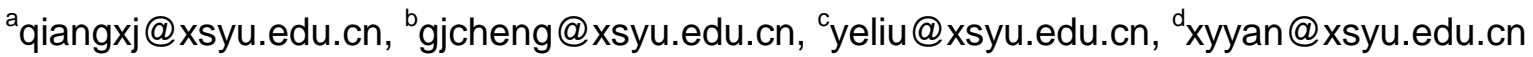

Keywords: Teaching; Learning; The Flipped Classroom; In-class; Out-of-class; Course

\begin{abstract}
The flipped classroom is a new pedagogical method, which employs asynchronous video lectures and practice problems as homework, and active, group-based problem solving activities in the classroom. It represents a unique combination of learning theories once thought to be incompatible. Active, problem-based learning activities founded upon a constructivist ideology and instructional lectures derived from direct instruction methods founded upon behaviorist principles. Among others, these include the type of in-class and out-of-class activities, the measures used to evaluate the study, and methodological characteristics for each study. Student perceptions of the flipped classroom are somewhat complex, but are mainly positive overall. Students tend to prefer in-person lectures to video lectures, but prefer interactive classroom activities over lectures. This paper provides course teaching design in universities of China based on the thought of the flipped classroom. Studies are characterized on several dimensions. It suggests that student learning is improved for the flipped compared to traditional classroom. It proposes to study the analysis of teaching effects with different patterns of Chinese university course. It also recommends that teachers consider carefully for leadership of university courses theory frame of the class activities design.
\end{abstract}

\section{Introduction}

There are two related movements that are combining to change the face of education. The first of these is a technological movement. This technological movement has enabled the spread and duplication of information at an extremely low-cost.

As technologies have been adopted, the ideas that have been spread through their channels have enabled a second movement. Whereas the technological movement sought to overcome real physical barriers to the free and open flow of information, this ideological movement seeks to remove the artificial, man-made barriers.

In the technological arena, researchers have made significant advances. Studies show that video lectures outperform in-person lectures, with interactive online videos doing even better. Online homework is just as effective as paper-and-pencil homework [1], and carefully developed intelligent tutoring systems have been shown to be just as effective as human tutors [2].

While online education is improving, expanding, and becoming openly available for free, university tuition at brick-and-mortar schools is rapidly rising [3]. As a result, the natural question being asked by both students and educational institutions is exactly what students are getting for their money.

Students are not the only ones demanding higher outcomes from educational institutions. There is also increasing pressure from accreditation institutions. Commonly referred to as outcomes $3 \mathrm{a}-\mathrm{k}$, these criteria include, "an ability to communicate effectively," and "an ability to identify, formulate, and solve engineering problems," as well as, "an ability to function on multidisciplinary teams." Many of these criterions are generally difficult to teach and assess effectively with informative lectures and closed form questions.

Problem-based learning methods, however, can be much more effective at achieving these goals. Felder and Brent survey research indicating that problem-based learning methods can be used to fulfill 
ABET 3a-k outcomes. However, adoption of problem-based learning is hindered by the fact that the course for engineering programs is already tightly packed. Although computer technology is to blame for at least a portion of the uncomfortable situation in which educational institutions find themselves, it may also form a key part of the solution. Rather, pre-recorded lectures can be assigned to students as homework, leaving class time open for interactive learning activities-activities that cannot be automated or computerized. This is the key concept behind what is becoming the new buzzword in educational circles: the flipped classroom.

\section{Defining the Flipped Classroom}

Despite the arguments around the flipped classroom as an exciting new topic in educational research, there is a lack of consensus on what exactly the flipped classroom is, and there is also a limited amount of scholarly research on its effectiveness. First, perhaps the simplest definition of the flipped (or inverted) classroom is given by Lage et al. [4]. "Inverting the classroom means that events that have traditionally taken place inside the classroom now take place outside the classroom and vice versa". While this explanation captures the rationale for using the terminology inverted or flipped, it does not adequately represent the practice of what researchers are calling the flipped classroom. This definition would imply that the flipped classroom merely represents a re-ordering of classroom and at-home activities.

Most researchers on the flipped classroom employs group-based interactive learning activities inside the classroom, citing student-centered learning theories based on the works of Piaget and Vygotsky. The exact nature of these activities varies widely between studies. Similarly, there is wide variation in what is being assigned as "homework". The flipped classroom label is most often assigned to courses that use activities made up of asynchronous web-based video lectures and closed-ended problems or quizzes. In many traditional courses, this represents all the instruction students ever get. Thus, the flipped classroom actually represents an expansion of the course, rather than a mere re-arrangement of activities.

The flipped classroom as an educational technique consists of two parts: interactive group learning activities inside the classroom, and direct computer-based individual instruction outside the classroom. We restrict this definition to exclude designs that do not employ videos as an outside of the classroom activity. While a broad conception of the flipped classroom may be useful, definitions that become too broad suggest that assigning reading outside of class and having discussions in class constitutes the flipped classroom.

\section{Theoretical Basis for the Flipped Classroom}

It is ready to discuss the theoretical frameworks used to guide the design of in-class activities. The theoretical foundations used for justifying the flipped classroom typically focus on reasons for not using classroom time to deliver lectures. It is important to note that while learning styles serves as a justification for differentiated learning activities, it does not necessarily provide a framework for how these activities should be structured. A brief overview of these student-centered learning theories and relevant literature is provided in the following sections.

Learning Styles. Learning styles theories posit that individuals have unique learning styles, and that matching learning experiences with particular learning styles improves educational outcomes. There are several strands within the learning styles literature, but extensive exploration of all of these is beyond the scope of the current work. Kolb's own model of learning styles is then based upon this theory. This model consists of a universal learning cycle and two embedded dimensions, perception and processing. Kolb's four learning styles are given by the permutations of these two dimensions. 
The learning styles theory of Felder and Silverman is also noteworthy, as this was developed specifically for use in engineering education. Felder and Silverman identify at least two sources for the dimensions of their model, including Jung's theory of psychological types and Kolb's learning styles. This model consists of five dimensions, with two extremes for each dimension - the permutation yields 32 learning styles. These dimensions include perception, input, organization, processing, and understanding. Corresponding categories for teaching styles are established along the dimensions of content, presentation, organization, student participation, and perspective.

Peer-Assisted, Collaborative, and Cooperative Learning. Topping and Ehly [5] define peer assisted learning as, "the acquisition of knowledge and skill through active helping and supporting among status equals or matched companions". This broad definition prepares us for the statement by Foot and Howe [6], "Taken together, the processes [collaborative learning and peer tutoring] describe and seek to explain underpin virtually all the [peer-assisted learning] techniques currently in educational practice". Smith and MacGregor further explain, "Cooperative learning represents the most carefully structured end of the collaborative learning continuum".

Cooperative Learning. Foot and Howe describe cooperative learning as including three key parts: 1) Students work in teams toward the attainment of some superordinate goal. 2) Labor is divided between team members, such that each individual takes responsibility for a different sub-goal. 3) Individual contributions are pooled into a composite product to ensure that the goal is reached.

Synthesizing the views of several theorists [7], Doolittle notes that while there is not perfect consensus on what constitutes cooperative learning, five factors are paramount: 1) Positive interdependence, 2) Face-to-face interaction, 3) Individual accountability, 4) Small group and interpersonal skills, 5) Group self-evaluation.

A Meta-analysis of the effects of cooperative learning methods is given by Slavin, and Johnson et al. The most effective of these is Learning Together \& Alone, which focuses on, "the integrated use of cooperative, competitive and individualistic learning" [8].

Problem-Based Learning. Hmelo-Silver lays out five goals of problem-based learning. These include helping students develop 1) Flexible knowledge, 2) Effective problem-solving skills, 3) Self-directed learning skills, 4) Effective collaboration skills, and 5) intrinsic motivation.

Barrows describes six characteristics of problem-based learning: 1) Learning is Student-Centered. 2) Learning Occurs in Small Student Groups. 3) Teachers are Facilitators or Guides. 4) Problems Form the Organizing Focus and Stimulus for Learning. 5) Problems are a vehicle for the development of clinical problem-solving skills. 6) New information is acquired through self-directed learning.

Dochy et al. and Gijbels et al. [9] indicate that the effect of PBL on skills is positive, while its effect on knowledge is negative. Combined results indicate an overall negative effect for problem based learning. Gijbels et al. recommend careful consideration of assessment methods in measuring problem-based learning outcomes.

Active Learning. Prince [10] defines active learning broadly as, "any instructional method that engages students in the learning process." This definition is itself broad enough to include many traditional classroom activities such as lectures. Thus, active learning acts as a superset for both peer-assisted and problem-based learning approaches. The researchers provide a broad sweep of the literature, highlighting evidence for active learning.

The importance of these (student-centered) learning theories to the flipped classroom cannot be understated. Without these, the flipped classroom simply does not exist. The flipped classroom is made up of two components: one component that requires human interaction (in-class activities), and a second component that is automated through the use of computer technologies such as video lectures (outside activities) [11]. Obviously, the classroom component is critical, and the student-centered learning theories just presented provide the philosophical basis for the design of these activities. But, some may overlook this fact and instead conceptualize the flipped classroom based only on the presence (or absence) of computer technology such as video lectures. 


\section{Course Teaching Design in Universities of China}

Many courses in colleges or universities in China currently are adopted the traditional classroom teaching mode. This has seriously affected the students learning courses. In order to better training talents, need educators to adopt new technologies as soon as possible, make use of new ideas, establish new teaching mode.

According to the university course practice in China, adopting the teaching mode based on the flipped classroom will become the choice of the times.

The combination of in-class and out-of-class activities is evaluated to determine whether the study actually represented a flipped classroom. To meet the touchstone, out-of-class activities must include required video lectures, in-class activities must be required, and must involve interactive learning activities - specifically, the primary in-class component could not be lectures. Some of these required students to read material before class, rather than having it presented in an audiovisual format, others maintained that either video lectures or in-class activities were optional.

Students are required to watch narrated PowerPoint videos and complete a worksheet before class time. In class, students participate in alternating ten-minute mini-lectures and five to eight minute active learning exercises. While these results are encouraging, there are several shortcomings to this study. First, in-class activities still carry a lecture component, even though time is provided for interactive activities. Second, the duration of the treatment is very short, and topics on both sides of the flipped topics are still taught with traditional methods. This leaves open the question of whether similar results will be achieved across all topics if the entire class were flipped.

Teachers conduct their study in a senior-level computer interaction course. They teach concurrent experimental and comparison sections of the course, and match sections on topics, assignments, and time on task. Students in the experimental section watch narrated PowerPoint videos outside of class, and participate in interactive learning activities inside class. Students in the flipped environment score significantly higher on all homework assignments, projects, and tests.

In summary, of all the studies on the flipped classroom, there is only one that has examined student performance throughout a semester. Further, the solution is very specific, rather than being based on established principles to guide adaptation. Thus, it is needed to examine the influence of flipped classroom instruction on objective learning outcomes in China.

\section{Summary}

At present, most of the teachers in colleges or universities of China generally adopt the traditional classroom teaching mode. This will seriously affect the quality of teaching in higher education. In order to better training talents, need teachers to adopt new technologies as soon as possible, make use of new thinking, reform in education. It suggests that in order to ensure progress, future teachers on the flipped classroom should engage controlled studies that objectively examine student performance throughout a semester, with both traditional and concept-inventory style problems. Further, it recommends that teachers applying the flipped classroom leverage the existing research and theoretical frameworks to guide their use and design of in-class activities. As a side-note, it recommends that teachers should clearly describe the activities used for both in-class and out-of-class activities. The recording technology and ubiquity web-based dissemination tools make course teaching on the flipped classroom in China both timely and cost-effective.

\section{References}

[1] H. Fynewever, A comparison of the effectiveness of web-based and paper-based homework for general chemistry. The Chemical Educator, 13(4):264-269, 2008. 
[2] Kurt VanLehn, The relative effectiveness of human tutoring, intelligent tutoring systems, and other tutoring systems. Educational Psychologist, 46(4):197-221, 2011.

[3] Information on https://nces.ed.gov/fastfacts/display.asp?id=76.

[4] M.J. Lage, G.J. Platt, and M. Treglia, Inverting the classroom: A gateway to creating an inclusive learning environment. The Journal of Economic Education, 31(1):30-43, 2000.

[5] Information on http://books.google.com/books?id=UZv6grfgeF4C.

[6] H. Foot, C. Howe, The psychoeducational basis of peer-assisted learning. In K.J. Topping and S.W. Ehly, editors, Peer-Assisted Learning, Lawrence Erlbaum Associates, 1998, pp. 27-43.

[7] Jeanne Ellis Ormrod. Educational psychology: Principles and applications. Merrill, 1995.

[8] D.W. Johnson and R.T. Johnson. Learning together and alone: Overview and meta-analysis. Asia Pacific Journal of Education, 22(1):95-105, 2002.

[9] D. Gijbels, F. Dochy, P. Van den Bossche, and M. Segers. Effects of problem-based learning: A meta-analysis from the angle of assessment. Review of educational research, 75(1):27-61, 2005.

[10] M. Prince. Does active learning work? A review of the research. Jounal of Engeneering Education-Washington, 93:223-232, 2004.

[11] Jeffery $\mathrm{S}$ Thomas and Timothy A. Philpot. An inverted teaching model for a mechanics of materials course.In Proceedings of the ASEE Annual Conference \& Exposition, 2012. 